\title{
Risk Factors for Peripheral Arterial Disease among Patients with Chronic Kidney Disease
}

\author{
Jing Chen, MD ${ }^{a},{ }^{\star}$, Emile R. Mohler III, MD ${ }^{b,{ }^{*}}$, Dawei Xie, PhD ${ }^{b}$, Michael G. Shlipak, MD ${ }^{c}$, \\ Raymond R. Townsend, MD ${ }^{b}$, Lawrence J. Appel, MD ${ }^{d}$, Dominic S. Raj, MD ${ }^{e}$, Akinlolu O. \\ Ojo, MD, PhD $^{f}$, Martin J. Schreiber, MD $^{g}$, Louise F. Strauss, MD $^{h}$, Xiaoming Zhang, MS $^{b}$, Xin \\ Wang, MS ${ }^{b}$, Jiang He, MD, PhD ${ }^{a}, \mathrm{i}$, L. Lee Hamm, MDa , and for the CRIC investigators \\ aTulane University School of Medicine, New Orleans, LA \\ bUniversity of Pennsylvania School of Medicine, Philadelphia, PA \\ cUniversity of California at San Francisco School of Medicine, CA \\ dJohns Hopkins University School of Medicine, Baltimore, MD \\ e'George Washington University School of Medicine, Washington, DC \\ fUniversity of Michigan School of Medicine, Ann Arbor, MI \\ ${ }^{9}$ Cleveland Clinic, Cleveland, $\mathrm{OH}$ \\ hUniversity Hospitals of Case Western Reserve University, Cleveland, $\mathrm{OH}$ \\ 'Tulane University School of Public Health and Tropical Medicine, New Orleans, LA
}

\section{Abstract}

\begin{abstract}
Patients with chronic kidney disease (CKD) have an increased risk of developing peripheral arterial disease (PAD). We examined the cross-sectional association between novel risk factors and prevalent PAD among patients with CKD. A total of 3,758 patients with an estimated glomerular filtration rate (eGFR) of $20-70 \mathrm{~mL} / \mathrm{min} / 1.73 \mathrm{~m}^{2}$ who participated in the chronic renal insufficiency cohort (CRIC) study were included in the current analysis. PAD was defined as an ankle-brachial index $<0.9$ or a history of arm or leg revascularization. After adjustment for age, sex, race, cigarette smoking, physical activity, history of hypertension and diabetes, pulse pressure, high-density lipoprotein cholesterol, eGFR, and CRIC clinical sites, several novel risk factors were significantly associated with PAD. For example, odds ratios (95\% confidence intervals) for a one standard deviation higher level of risk factors were $1.18(1.08-1.29)$ for logtransformed high sensitivity-C reactive protein, 1.18 (1.08-1.29) for white blood cell count, 1.15 (1.05-1.25) for fibrinogen, 1.13 (1.03-1.24) for uric acid, 1.14 (1.02-1.26) for hemoglobin A1c, $1.11(1.00-1.23)$ for log-transformed homeostasis model assessment-insulin resistance, and 1.35 (1.18-1.55) for cystatin C. In conclusion, these data indicate that inflammation, prothrombotic state, oxidative stress, insulin resistance, and cystatin $\mathrm{C}$ were associated with an increased
\end{abstract}

\footnotetext{
(C) 2012 Excerpta Medica, Inc. All rights reserved.

Corresponding author (to whom reprint requests should be addressed): Jing Chen, MD, MSc, Department of Medicine, Tulane University School of Medicine, 1430 Tulane Ave., SL-45, New Orleans, LA 70112, Phone: 504-988-5346; Fax: 504-988-1909, jchen@tulane.edu.

Drs. Chen and Mohler contributed equally to this article

Publisher's Disclaimer: This is a PDF file of an unedited manuscript that has been accepted for publication. As a service to our customers we are providing this early version of the manuscript. The manuscript will undergo copyediting, typesetting, and review of the resulting proof before it is published in its final citable form. Please note that during the production process errors may be discovered which could affect the content, and all legal disclaimers that apply to the journal pertain.
} 
prevalence of PAD in patients with CKD. Further studies are warranted to examine the causal effect of these risk factors on PAD in CKD patients.

\section{Keywords}

peripheral arterial disease; novel risk factors; chronic kidney disease

It is well established that older age, cigarette smoking, physical inactivity, hypertension, diabetes, and hypercholesterolemia play an important role in the initiation and development of atherosclerosis and its clinical manifestations, including PAD. ${ }^{1}$ However, these traditional risk factors do not entirely explain the excess risk of PAD among some individuals, such as CKD patients. ${ }^{2,3}$ The identification of novel risk factors for PAD may help develop strategies for the prevention and treatment of PAD among patients with CKD. The Chronic Renal Insufficiency Cohort (CRIC) study is a large prospective cohort study of patients with varying degrees of CKD aimed at investigating risk factors for the progression of CKD and development of CVD. ${ }^{4}$ In the present analysis, we examine the association between a panel of novel CVD risk factors and prevalence of PAD after adjustment for established CVD risk factors in CKD patients.

\section{Methods}

The CRIC study participants include a racially and ethnically diverse group of men and women who were aged 21 to 74 years old and had CKD based on age-based estimated GFR (eGFR) ${ }^{4}$ A total of 3,939 CRIC participants were recruited between May 2003 and August 2008 from seven clinical centers in the US. ${ }^{5}$ Participants were identified through searches of laboratory databases, medical records, and referrals from health care providers. Patients with cirrhosis, HIV infection, polycystic kidney disease, or renal cell carcinoma, those on dialysis or recipients of a kidney transplant, or those taking immunosuppressant drugs were excluded. In the current analysis, participants with both a history of amputation and an ABI $>0.9(n=89)$, or an ABI >1.4 ( $n=92)$ were excluded due to uncertainty of their PAD status. After exclusion, 3,758 CRIC participants were included in the analysis.

This study was approved by the Institutional Review Boards for each of the participating clinical centers and the scientific and data coordinating center. Written informed consent was obtained from all participants. This study also conformed to the Health Insurance Portability and Accountability Act (HIPAA) guidelines.

All study data were collected by trained study staff during the CRIC clinical visits. All data collection procedures and equipment were standardized across study sites. A baseline medical history questionnaire was administered in which participants were queried about their prior history of PAD (claudication, amputation or angioplasty and procedures to open up blood vessels in arm or legs). Questionnaires also assessed demographic characteristics and lifestyle risk factors. Current smoker was defined as the participants who currently smoked and smoked more than 100 cigarettes in their lifetime. Former smoker was defined as the participants who smoked more than 100 cigarettes in their lifetime in the past. Alcohol drinker was defined as the participants who consumed one or more beverages containing alcohol each week over the previous year. Body weight and height were each measured twice and averaged for analysis. Body mass index (BMI) was calculated as weight in kilograms divided by height in meters squared. Waist circumference was measured at the uppermost lateral border of the iliac crest with a Gulick II tape and repeated until two measures agreed within 1 centimeter. Three seated blood pressure (BP) measurements were obtained by trained and certified staff after at least 5 minutes of quiet rest. These 
measurements were performed according to a standard protocol using an aneroid sphygmomanometer. ${ }^{6}$ The measurements were averaged as baseline systolic and diastolic BP for analysis. Pulse pressure was calculated by subtracting diastolic BP from systolic BP. Hypertension was defined as systolic BP $\geq 140 \mathrm{mmHg}$ and/or diastolic BP $\geq 90 \mathrm{mmHg}$ and/or current use of antihypertensive medication.

ABI was obtained per standard protocol. After the participant rested supine for 5 minutes, systolic BP was measured in both arms with the appropriate-sized arm cuff. For each leg, systolic BP in each posterior tibial (PT) and dorsalis pedis (DP) artery was measured. All pressures were detected with a continuous-wave Doppler ultrasound probe. The leg-specific ABI was calculated by dividing the higher systolic BP in the PT or DP by the higher of the right or left brachial systolic BPs. PAD was defined as an $\mathrm{ABI}<0.9$ or history of arm or leg revascularization in the current analysis.

Blood glucose, cholesterol, triglycerides, glycated hemoglobin (HbA1c), phosphate, calcium, alkaline phosphatase, total parathyroid hormone, uric acid, hemoglobin, albumin, bicarbonate, and white blood cell counts (WBC) were measured using standard laboratory methods. Serum high sensitive C-reactive protein (hsCRP), homocysteine, and cystatin C were measured by a particle enhanced immunonephelometry method. Fibrinogen was measured using an immunochemical reaction method. Serum myeloperoxidase was measured using a chemiluminescent microparticle immunoassay (Abbott Diag. Architect ci8200). Urinary albumin was measured by radioimmunoassay (RIA). Diabetes was defined as a fasting glucose $\geq 126 \mathrm{mg} / \mathrm{dL}$, a random glucose $\geq 200 \mathrm{mg} / \mathrm{dL}$, and/or use of insulin or other anti-diabetic medication. Estimated-GFR (eGFR) was calculated using the reexpressed Modification of Diet in Renal Disease (MDRD) equation after calibrating serum creatinine measurements to isotope dilution mass spectrometry-traceable values. ${ }^{7} \mathrm{~A}$ homeostasis model assessment (HOMA) was calculated to evaluate insulin resistance using the following formula: fasting serum insulin $(\mu \mathrm{U} / \mathrm{mL})$-fasting plasma glucose $(\mathrm{mmol} / \mathrm{L}) /$ 22.5. ${ }^{8}$ Albumin corrected calcium levels were calculated as follows: serum calcium $(\mathrm{mg} / \mathrm{dL})$ $+\left[0.8 \times(4-\right.$ serum albumin $(\mathrm{g} / \mathrm{dL})] \cdot{ }^{9}$ All laboratory measurements were performed at the CRIC Central Clinical Laboratory at the University of Pennsylvania.

Baseline characteristics of participants were summarized as means (standard deviation, SD) for continuous variables and percentages for categorical variables by PAD status. Statistical significance was tested using ANOVA for continuous variables and the $\chi^{2}$ test for categorical variables. Multiple logistic regression analyses were used to explore the associations of PAD with traditional and novel CVD risk factors. In the multiple traditional risk factor model, all demographic variables and traditional risk factors which were significant in univariate analysis, including age, sex, race/ethnicity, cigarette smoking, history of hypertension and diabetes, physical activity (total metabolic equivalent [MET]/ week), HDL-cholesterol, pulse pressure, eGFR, and 13 CRIC clinic sites were simultaneously included. In the multivariable analysis of novel CVD risk factors, two sets of covariables were adjusted. First, demographic variables, including age, sex, race, and CRIC clinical sites were adjusted. Then, traditional CVD risk factors, including cigarette smoking, physical activity, diabetes, hypertension, HDL-cholesterol, pulse pressure, and eGFR were included. Odds ratios and 95\% confidence intervals (CI) of PAD associated with categorical variables or one SD increase in continuous variables were presented. For those novel risk factors which were not normally distributed, including HOMA-insulin resistance, hsCRP, total parathyroid hormone, and myeloperoxidase, the log transformation was taken. All analyses were conducted using SAS v9.1 (Cary, NC). All p-values were two-sided and statistical significance was defined as $\mathrm{p}<0.05$. 


\section{Results}

Characteristics of CRIC participants by PAD status are provided in Table 1.

The age-gender-race-clinic-adjusted prevalence of PAD according to eGFR levels by diabetes status is displayed in figure 1. There was a significant, graded, and inverse association between eGFR and prevalence of PAD among patients with and without diabetes (p-value for trend $<0.0001$ for both groups). The prevalence of PAD was also significantly higher in patients with diabetes compared to those without, stratified by eGFR categories ( $\mathrm{p}$ value for group difference $<0.0001$ ).

The odds ratios $(95 \% \mathrm{CI})$ of PAD associated with traditional risk factors from a multivariable model are shown in Table 2. Age, black race, former and current cigarette smoking, history of diabetes, and pulse pressure were positively and significantly associated with the odds of PAD, while physical activity, HDL-cholesterol, and eGFR were inversely and significantly associated with the odds of PAD.

The age-gender-race-clinic-adjusted and multivariate-adjusted odds ratios of PAD associated with novel risk factors are shown in Table 3. After adjusting for demographic variables, higher levels of phosphate, calcium phosphate product, alkaline phosphatase, logtransformed total parathyroid hormone, log-transformed hsCRP, WBC, homocysteine, fibrinogen, uric acid, log-transformed myeloperoxidase, HbA1c, log-transformed HOMAinsulin resistance, cystatin $\mathrm{C}$ and urine albuminuria were significantly associated with higher odds of PAD, while higher levels of albumin and hemoglobin were significantly associated with lower odds of PAD. After further adjusting for multiple traditional CVD risk factors, hsCRP, WBC, fibrinogen, uric acid, myeloperoxidase, HbA1c, HOMA-insulin resistance, and cystatin $\mathrm{C}$ remained significantly associated with higher odds of PAD.

We tested the interactions between diabetes and novel risk factors on PAD. Among 16 tested novel risk factors, we found 2 significant interactions: odds ratios of PAD associated with HbAlc were $1.52(95 \%$ CI $0.98,2.38)$ in diabetic patients and $1.10(95 \%$ CI $0.98,1.22)$ in non-diabetic patients ( $\mathrm{p}=0.02$ for interaction); odds ratios of PAD associated with urine albumin excretion were $0.72(95 \%$ CI $0.50,1.03)$ in diabetic patients and $1.12(95 \%$ CI 1.10 , 1.53 ) in non-diabetic patients ( $\mathrm{p}=0.02$ for interaction). However, these interactions were not statistically significant after multiple comparisons were taken into account. In addition, there was no significant interaction between parathyroid hormone and cystatin $C(p=0.09)$.

\section{Discussion}

The present study identified a significant association between several novel CVD risk factors and PAD among patients with CKD. The prevalence of PAD increased with higher levels of hsCRP, WBC, fibrinogen, uric acid, myeloperoxidase, HbA1c, HOMA-insulin resistance, and cystatin $\mathrm{C}$. These relationships were independent of traditional CVD risk factors. Our findings are noteworthy, because this is the first study to report a significant association of hsCRP, WBC, fibrinogen, uric acid, myeloperoxidase, HbA1c, HOMAinsulin resistance, and cystatin $\mathrm{C}$ with the prevalence of $\mathrm{PAD}$ among a large sample of $\mathrm{CKD}$ patients. In addition, numerous CVD risk factors were measured and adjusted in the multivariable analyses. Furthermore, careful measures of study exposure and outcome variables allowed for precise estimation of the association.

These findings have important clinical and public health implications because patients with CKD have an increased risk of developing PAD. ${ }^{10,11}$ Identifying novel risk factors for PAD may help develop strategies for the prevention and treatment of PAD among patients with CKD. The current study provides new and important information on novel risk factors for 
PAD among CKD patients. Wattanakit et al reported that reduced kidney function was significantly associated with development of PAD in the Atherosclerosis Risk in Communities (ARIC) study. ${ }^{10} \mathrm{Ix}$ et al also reported an inverse association of eGFR with risk of a $\mathrm{ABI}<0.9$ in an elderly population. ${ }^{11}$ Our study indicated that there was a significant inverse relationship between eGFR levels and prevalence of PAD in CKD patients with and without diabetes.

The underlying reason for the increased risk of PAD among patients with CKD is not well understood. In this study, we found that traditional risk factors such as age, black race, cigarette smoking, diabetes, and pulse pressure were associated with an increased prevalence of PAD among CKD patients. In addition, we found that higher physical activity and serum HDL-cholesterol level were associated with lower prevalence of PAD.

Allison et al examined the association between novel risk factors and PAD among general populations and reported that one standard deviation higher levels of homocysteine, CRP, and fibrinogen were associated with increased odds for PAD of 1.15, 1.29, and 1.31-fold, respectively, after adjustment for traditional risk factors for PAD. ${ }^{12}$ Recently, Pande and collegues also reported that CRP and insulin resistance were associated with increased risk of PAD in the general population. ${ }^{13}$ In addition, Shankar et al reported that higher serum uric acid levels were positively associated with PAD, independent of smoking, BMI, hypertension, diabetes, serum total cholesterol, serum creatinine, and other confounders among 3,987 National Health and Nutrition Examination Survey 1999-2002 participants. ${ }^{14}$ Very few studies have examined the novel risk factors for PAD in patients with CKD. Jaar et al reported that homocysteine was associated with risk of PAD in incident-dialysis patients. ${ }^{15}$ To our knowledge, this study is the first investigation into novel risk factors for PAD in predialysis CKD patients. Our data suggested that hsCRP, WBC, fibrinogen, uric acid, myeloperoxidase, HbA1c, HOMA-insulin resistance, and cystatin C increase the prevalence of PAD in CKD patients independent of traditional CVD risk factors including hypertension, diabetes and kidney function.

Both hsCRP and fibrinogen are circulating acute-phase reactants that increase manyfold during the inflammatory response to tissue injury or infectious triggers. ${ }^{16} \mathrm{WBC}$ is also an inflammatory marker. Our study suggests that systemic inflammation might contribute to development of PAD in CKD patients.

Uric acid is one of the major plasma antioxidants, but it could also manifest pro-oxidant properties and promote lipid oxidation in vascular tissue. ${ }^{17,18} \mathrm{In}$ addition, an experimental study suggested that uric acid may induce inflammation and reduce nitric oxide release from vascular cells. ${ }^{19}$ It is likely that uric acid increases the risk of PAD in CKD patients through the mechanism of oxidative stress, inflammation, and endothelial dysfunction. Further study is warranted to examine this significant issue.

Hemoglobin A1c and HOMA-insulin resistance were associated with PAD in our study independent of a history of diabetes. Previous data suggested that there was a positive and independent association between HbA1c and PAD risk in adults with or without diabetes..$^{20,21}$ In addition, insulin resistance was associated with PAD in the US general population. ${ }^{13}$ These data combined with our findings support the notion that higher levels of $\mathrm{HbA1c}$ and insulin resistance are associated with an increased risk of PAD in CKD patients.

A previous study suggested that elevated cystatin $\mathrm{C}$ is independently predictive of incident PAD events among elderly patients. ${ }^{22}$ Our data indicate that the association of cystatin C with prevalence of PAD is independent of creatinine-based eGFR, which suggests that cystatin $\mathrm{C}$ may represent residual kidney function that is not precisely captured by serum creatinine. In addition, cystatin $\mathrm{C}$ was associated with inflammation and might be a marker 
of systemic inflammation. ${ }^{23}$ The causal relationship of cystatin C to PAD remains to be explored.

Potential limitations of our study should be noted. First, this cross-sectional analysis cannot establish a temporal relationship between the risk factors and PAD. Some of these risk factors could be an effect of the disease itself rather than a cause. Therefore, future longitudinal study and clinical trials are warranted to establish a causal relationship. In addition, serum creatinine-based eGFR was used to define renal function in our study. Although inulin or iothalamate clearance techniques may provide a more sensitive estimate of renal function, serum creatinine-based eGFR has been used widely in large epidemiologic studies and in clinical practice. As such, the findings from our study are applicable to clinical and public health practice settings. Furthermore, the insulin resistance was not measured using the gold standard method, i.e., the hyperinsulinemic-euglycemic clamp, as this method is impractical in a large-study setting. HOMA-insulin resistance level has been found to be an appropriate surrogate indicator for the insulin sensitivity clamp across a broad spectrum of insulin sensitivity and glucose tolerance levels and is considered to be suitable for use in epidemiologic studies by the American Diabetes Association. ${ }^{24}$ HOMAinsulin resistance has also been validated among CKD patients. ${ }^{25}$

\section{Acknowledgments}

The CRIC study was supported by the National Institute of Diabetes and Digestive and Kidney Diseases under a cooperative agreement (5U01DK060990, 5U01DK060984, 5U01DK06102, 5U01DK061021, 5U01DK061028, 5U01DK60980, 5U01DK060963, and 5U01DK060902). In addition, this work was supported in part by the following institutional Clinical Translational Science Awards and other National Institutes of Health grants: Johns Hopkins University UL1 RR-025005, University of Maryland GCRC M01 RR-16500, Case Western Reserve University Clinical and Translational Science Collaborative (University Hospitals of Cleveland, Cleveland Clinic Foundation, and MetroHealth) UL1 RR-024989, University of Michigan GCRC M01 RR-000042 and CTSA UL1 RR-024986, University of Illinois at Chicago Clinical Research Center, M01 RR-013987-06, Tulane/LSU/Charity Hospital General Clinical Research Center RR-05096, and Kaiser NIH/NCRR UCSF-CTSI UL1 RR-024131 and 5K24DK002651. Additional support was provided by the National Center for Minority Health and Health Disparities, National Institutes of Health, Bethesda, MD. We would like to express our special thanks to Lisa Nessel for her assistance during the preparation of this manuscript and to the CRIC participants for their commitment to this study.

\section{References}

1. DeLoach SS, Mohler ER III. Peripheral arterial disease: a guide for nephrologists. Clin J Am Soc Nephrol. 2007; 2:839-846. [PubMed: 17699501]

2. Brevetti G, Giugliano G, Brevetti L, Hiatt WR. Inflammation in peripheral artery disease. Circulation. 2010; 122:1862-1875. [PubMed: 21041698]

3. Brevetti G, Schiano V, Chiariello M. Endothelial dysfunction: a key to the pathophysiology and natural history of peripheral arterial disease? Atherosclerosis. 2008; 197:1-11. [PubMed: 18076886]

4. Feldman HI, Appel LJ, Chertow GM, Cifelli D, Cizman B, Daugirdas J, Fink JC, Franklin-Becker ED, Go AS, Hamm LL, He J, Hostetter T, Hsu CY, Jamerson K, Joffe M, Kusek JW, Landis JR, Lash JP, Miller ER, Mohler ER 3rd, Muntner P, Ojo AO, Rahman M, Townsend RR, Wright JT. Chronic Renal Insufficiency Cohort (CRIC) Study Investigators. The Chronic Renal Insufficiency Cohort (CRIC) Study: Design and Methods. J Am Soc Nephrol. 2003; 14:S148-153. [PubMed: 12819321]

5. Lash JP, Go AS, Appel LJ, He J, Ojo A, Rahman M, Townsend RR, Xie D, Cifelli D, Cohan J, Fink JC, Fischer MJ, Gadegbeku C, Hamm LL, Kusek JW, Landis JR, Narva A, Robinson N, Teal V, Feldman HI. Chronic Renal Insufficiency Cohort (CRIC) Study Group. Chronic Renal Insufficiency Cohort (CRIC) Study: baseline characteristics and associations with kidney function. Clin J Am Soc Nephrol. 2009; 4:1302-1311. [PubMed: 19541818] 
6. Perloff D, Grim C, Flack J, Frohlich ED, Hill M, McDonald M, Morgenstern BZ. Human blood pressure determination by sphygmomanometry. Circulation. 1993; 88:2460-2470. [PubMed: 8222141]

7. Levey AS, Coresh J, Greene T, Stevens LA, Zhang YL, Hendriksen S, Kusek JW, Van Lente F. Chronic Kidney Disease Epidemiology Collaboration. Using standardized serum creatinine values in the modification of diet in renal disease study equation for estimating glomerular filtration rate. Ann Intern Med. 2006; 145:247-254. [PubMed: 16908915]

8. Matthews DR, Hosker JP, Rudenski AS, Naylor BA, Treacher DF, Turner RC. Homeostasis model assessment: insulin resistance and $\beta$-cell function from fasting plasma glucose and insulin concentration in man. Diabetologia. 1985; 28:412-419. [PubMed: 3899825]

9. Eknoyan G, Levin A, Levin NW. K/DOQI clinical practice guidelines for bone metabolism and disease in chronic kidney disease. Am J Kidney Dis. 2003; 42 (4 suppl 3):S1-201. [PubMed: 14520607]

10. Wattanakit K, Folsom AR, Selvin E, Coresh J, Hirsch AT, Weatherley BD. Kidney function and risk of peripheral arterial disease: results from the Atherosclerosis Risk in Communities (ARIC) Study. J Am Soc Nephrol. 2007; 18:629-636. [PubMed: 17215445]

11. Ix JH, Katz R, De Boer IH, Kestenbaum BR, Allison MA, Siscovick DS, Newman AB, Sarnak MJ, Shlipak MG, Criqui MH. Association of chronic kidney disease with the spectrum of ankle brachial index, the CHS (Cardiovascular Health Study). J Am Coll Cardiol. 2009; 54:1176-1184. [PubMed: 19761940]

12. Allison MA, Criqui MH, McClelland RL, Scott JM, McDermott MM, Liu K, Folsom AR, Bertoni AG, Sharrett AR, Homma S, Kori S. The effect of novel cardiovascular risk factors on the ethnicspecific odds for peripheral arterial disease in the Multi-Ethnic Study of Atherosclerosis (MESA). J Am Coll Cardiol. 2006; 48:1190-1197. [PubMed: 16979004]

13. Pande RL, Perlstein TS, Beckman JA, Creager MA. Association of insulin resistance and inflammation with peripheral arterial disease: the National Health and Nutrition Examination Survey, 1999 to 2004. Circulation. 2008; 118:33-41. [PubMed: 18559705]

14. Shankar A, Klein BE, Nieto FJ, Klein R. Association between serum uric acid level and peripheral arterial disease. Atherosclerosis. 2008; 196:749-755. [PubMed: 17275005]

15. Jaar BG, Plantinga LC, Astor BC, Fink NE, Longenecker C, Tracy RP, Marcovina SM, Powe NR, Coresh J. Novel and traditional cardiovascular risk factors for peripheral arterial disease in incident-dialysis patients. Adv Chronic Kidney Dis. 2007; 14:304-313. [PubMed: 17603986]

16. Hackam DG, Anand SS. Emerging risk factors for atherosclerotic vascular disease: a critical review of the evidence. JAMA. 2003; 290:932-940. [PubMed: 12928471]

17. Nieto FJ, Iribarren C, Gross MD, Comstock GW, Cutler RG. Uric acid and serum antioxidant capacity: a reaction to atherosclerosis? Atherosclerosis. 2000; 148:131-139. [PubMed: 10580179]

18. Bagnati M, Perugini C, Cau C, Bordone R, Albano E, Bellomo G. When and why a water-soluble antioxidant becomes pro-oxidant during copper-induced low-density lipoprotein oxidation: a study using uric acid. Biochem J. 1999; 340:143-152. [PubMed: 10229669]

19. Kang DH, Park SK, Lee IK, Johnson RJ. Uric acid-induced C-reactive protein expression: implication on cell proliferation and nitric oxide production of human vascular cells. J Am Soc Nephrol. 2005; 16:3553-3562. [PubMed: 16251237]

20. Selvin E, Wattanakit K, Steffes MW, Coresh J, Sharrett AR. HbA1c and peripheral arterial disease in diabetes: the Atherosclerosis Risk in Communities study. Diabetes Care. 2006; 29:877-882. [PubMed: 16567831]

21. Muntner P, Wildman RP, Reynolds K, Desalvo KB, Chen J, Fonseca V. Relationship between HbA1c level and peripheral arterial disease. Diabetes Care. 2005; 28:1981-1987. [PubMed: 16043742]

22. O'Hare AM, Newman AB, Katz R, Fried LF, Stehman-Breen CO, Seliger SL, Siscovick DS, Shlipak MG. Cystatin C and incident peripheral arterial disease events in the elderly: results from the Cardiovascular Health Study. Arch Intern Med. 2005; 165:2666-2670. [PubMed: 16344426]

23. Singh D, Whooley MA, Ix JH, Ali S, Shlipak MG. Association of cystatin C and estimated GFR with inflammatory biomarkers: the Heart and Soul Study. Nephrol Dial Transplant. 2007; 22:1087-1092. [PubMed: 17210589] 
24. American Diabetes Association. Consensus development conference on insulin resistance: 5-6 November 1997: American Diabetes Association. Diabetes Care. 1998; 21:310-314. [PubMed: 9540000]

25. Crutchlow MF, Robinson B, Pappachen B, Wimmer N, Cucchiara AJ, Cohen D, Townsend R. Validation of steady-state insulin sensitivity indices in chronic kidney disease. Diabetes Care. 2007; 30:1813-1818. [PubMed: 17468355] 


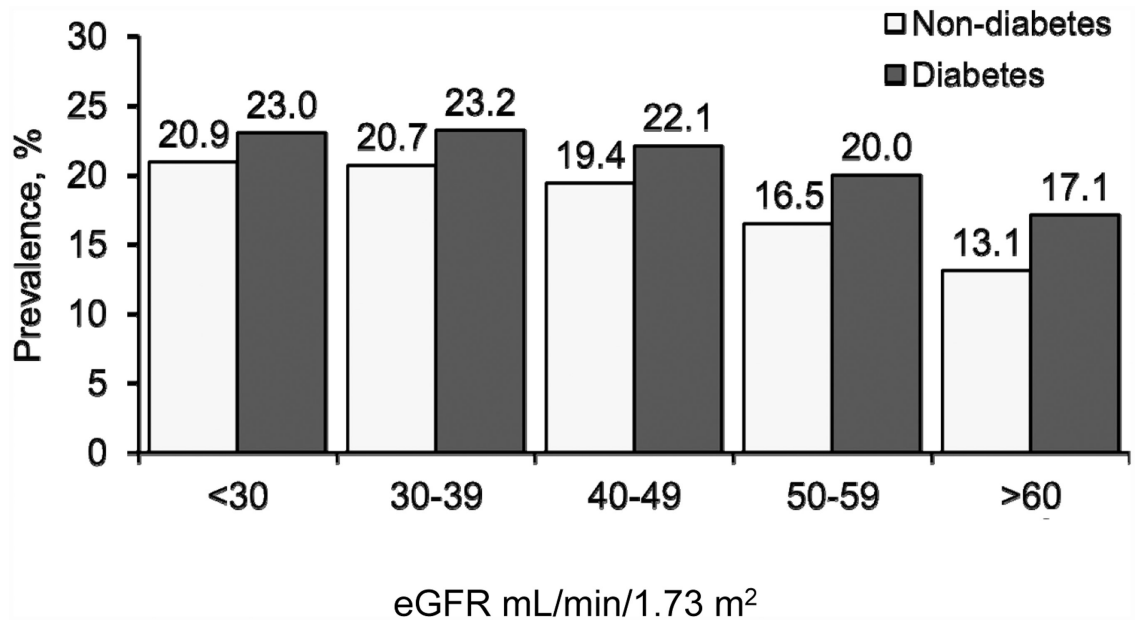

Figure 1. Age-gender-race-clinical site-adjusted prevalence of peripheral artery disease according to eGFR levels in patients with chronic kidney disease by diabetes status ( $p$ value for trend $<\mathbf{0 . 0 0 0 1}$ for both groups) 
Table 1

Demographic, lifestyle, clinical and biochemical characteristics of study participants according to peripheral artery disease

\begin{tabular}{|c|c|c|c|}
\hline \multirow{2}{*}{ Variables } & \multicolumn{2}{|c|}{ Peripheral Artery Disease } & \multirow{2}{*}{ P-value } \\
\hline & Yes $(n=754)$ & $(\mathbf{n}=\mathbf{3 0 0})$ & \\
\hline Age (years) & $62.2(9.1)$ & $57.2(11.2)$ & $<0.0001$ \\
\hline Male & $53.4 \%$ & $54.6 \%$ & 0.58 \\
\hline \multicolumn{4}{|l|}{ Race/ethnicity } \\
\hline White & $39.5 \%$ & $48.0 \%$ & \\
\hline Black & $50.1 \%$ & $40.4 \%$ & $<0.0001$ \\
\hline Other & $10.3 \%$ & $11.6 \%$ & \\
\hline High school education & $71.4 \%$ & $81.8 \%$ & $<0.0001$ \\
\hline Physical activity (MET/week) & $165.07(119.8)$ & $208.04(150.7)$ & $<0.0001$ \\
\hline \multicolumn{4}{|l|}{ Cigarette smoking } \\
\hline Never smoker & $29.6 \%$ & $48.6 \%$ & \\
\hline Former smoker & $51.1 \%$ & $39.6 \%$ & $<0.0001$ \\
\hline Current smoker & $19.4 \%$ & $11.8 \%$ & \\
\hline Alcohol drinker & $14.6 \%$ & $22.1 \%$ & $<0.0001$ \\
\hline Hypertension & $93.2 \%$ & $84.1 \%$ & $<0.0001$ \\
\hline Diabetes mellitus & $64.6 \%$ & $42.3 \%$ & $<0.0001$ \\
\hline Body mass index $\left(\mathrm{kg} / \mathrm{m}^{2}\right)$ & $32.9(8.6)$ & $31.8(7.6)$ & 0.0003 \\
\hline Waist circumference $(\mathrm{cm})$ & $108.3(17.9)$ & $105.0(17.4)$ & $<0.0001$ \\
\hline Pulse pressure $(\mathrm{mmHg})$ & $65.1(19.8)$ & $54.5(18.3)$ & $<0.0001$ \\
\hline High density lipoprotein cholesterol (mg/dL) & $45.3(14.3)$ & $48.2(15.8)$ & $<0.0001$ \\
\hline Low-density lipoprotein cholesterol (mg/dL) & $99.7(34.8)$ & $103.9(35.3)$ & 0.004 \\
\hline Calcium (mg/dL) & $9.16(0.56)$ & $9.20(0.50)$ & 0.07 \\
\hline Phosphate (mg/dL) & $3.83(0.71)$ & $3.68(0.65)$ & $<0.0001$ \\
\hline Calcium phosphate product & $35.0(6.64)$ & $33.9(6.21)$ & $<0.0001$ \\
\hline Alkaline phosphatase (U/L) & $96.7(36.4)$ & $90.5(34.3)$ & $<0.0001$ \\
\hline Log [total parathyroid hormone $(\mathrm{pg} / \mathrm{mL})]$ & $4.2(0.75)$ & $4.0(0.69)$ & $<0.0001$ \\
\hline $\log [$ high sensitivity C-reactive protein $(\mathrm{mg} / \mathrm{L})]$ & $1.20(1.26)$ & $0.87(1.26)$ & $<0.0001$ \\
\hline White blood cells (thousand/uL) & $7.08(3.12)$ & $6.45(1.97)$ & $<0.0001$ \\
\hline Homocysteine $(\mu \mathrm{mol} / \mathrm{L})$ & $16.6(6.43)$ & $14.6(5.94)$ & $<0.0001$ \\
\hline Fibrinogen (mg/dL) & $4.52(1.29)$ & $4.05(1.16)$ & $<0.0001$ \\
\hline Uric acid $(\mathrm{mg} / \mathrm{dL})$ & $7.82(1.98)$ & $7.29(1.89)$ & $<.0 .0001$ \\
\hline Log [myeloperoxidase (pmol/L)] & $4.82(0.97)$ & $4.65(1.18)$ & 0.0004 \\
\hline Serum albumin $(g / d L)$ & $3.87(0.48)$ & $3.97(0.46)$ & $<0.0001$ \\
\hline Hemoglobin $(\mathrm{g} / \mathrm{dL})$ & $12.2(1.71)$ & $12.8(1.77)$ & $<0.0001$ \\
\hline Hemoglobin A1c (\%) & $7.07(1.53)$ & $6.51(1.53)$ & $<0.0001$ \\
\hline Homeostasis model assessment-insulin resistance & $8.1(9.7)$ & $6.2(8.1)$ & $<0.0001$ \\
\hline Estimated glomerular filtration rate $\left(\mathrm{ml} / \mathrm{min} / 1.73 \mathrm{~m}^{2}\right)$ & $38.6(12.2)$ & $44.1(13.6)$ & $<0.0001$ \\
\hline Cystatin C (mg/L) & $1.74(0.56)$ & $1.45(0.52)$ & $<0.0001$ \\
\hline
\end{tabular}




\begin{tabular}{lccc}
\hline \multirow{2}{*}{ Variables } & \multicolumn{2}{c}{ Peripheral Artery Disease } & \multirow{2}{*}{ P-value } \\
\cline { 2 - 3 } & Yes (n=754) & $(\mathbf{n}=\mathbf{3 0 0})$ & \\
\hline Urinary albumin (g//24-hours) & $0.91(2.14)$ & $0.6(1.43)$ & $<0.001$ \\
\hline
\end{tabular}


Table 2

Odds ratios $(95 \%$ confidence intervals) of peripheral artery disease associated with traditional cardiovascular risk factors

\begin{tabular}{|c|c|c|}
\hline Variables & Odds Ratios $(95 \% \mathrm{CI})^{*}$ & P-value \\
\hline Age (5 year) & $1.19(1.13,1.25)$ & $<0.0001$ \\
\hline Male & $0.83(0.69,1.01)$ & 0.065 \\
\hline \multicolumn{3}{|l|}{ Race/ethnicity } \\
\hline White & 1.00 (reference) & \\
\hline Black & $1.24(1.02,1.51)$ & 0.098 \\
\hline Other & $1.01(0.68,1.49)$ & \\
\hline \multicolumn{3}{|l|}{ Cigarette smoker } \\
\hline Never smoker & 1.00 (reference) & \\
\hline Former smoker & $1.78(1.46,2.17)$ & $<0.0001$ \\
\hline Current smoker & $2.68(2.06,3.49)$ & \\
\hline Diabetes mellitus & $1.75(1.45,2.12)$ & $<0.0001$ \\
\hline Hypertension & $1.15(0.83,1.60)$ & 0.41 \\
\hline Physical activity (146 METs/week $\left.{ }^{\dagger}\right)$ & $0.87(0.78,0.97)$ & 0.01 \\
\hline High density lipoprotein cholesterol $\left(16 \mathrm{mg} / \mathrm{dL}^{\dagger}\right)$ & $0.83(0.74,0.91)$ & 0.0003 \\
\hline Pulse pressure $\left(19 \mathrm{mmHg}{ }^{\dagger}\right)$ & $1.30(1.18,1.43)$ & $<0.0001$ \\
\hline Estimated glomerular filtration rate $\left(14 \mathrm{ml} / \mathrm{min}\right.$ per $\left.1.73 \mathrm{~m}^{2}\right)$ & $0.74(0.67,0.82)$ & $<0.0001$ \\
\hline
\end{tabular}


Table 3

Odds ratios $(95 \%$ confidence intervals) of peripheral artery disease associated with novel cardiovascular risk factors

\begin{tabular}{|c|c|c|c|c|}
\hline \multirow{2}{*}{ Variables $*$} & \multicolumn{2}{|c|}{ Age-sex-race-clinical site-adjusted } & \multicolumn{2}{|c|}{ Multivariable-adjusted ${ }^{\dagger}$} \\
\hline & Odds ratio $(95 \% \mathrm{CI})$ & P-value & Odds ratio $(95 \%$ CI $)$ & P-value \\
\hline Corrected calcium $(0.5 \mathrm{mg} / \mathrm{dL})$ & $1.01(0.93,1.10)$ & 0.76 & $0.99(0.91,1.08)$ & 0.87 \\
\hline Phosphate $(0.7 \mathrm{mg} / \mathrm{dL})$ & $1.24(1.14,1.35)$ & $<0.0001$ & $1.03(0.93,1.13)$ & 0.57 \\
\hline Calcium phosphate product (6.6) & $1.23(1.13,1.35)$ & $<0.0001$ & $1.02(0.93,1.13)$ & 0.64 \\
\hline lkaline phosphatase, (34.8 U/L) & $1.13(1.04,1.22)$ & 0.003 & $1.01(0.92,1.10)$ & 0.87 \\
\hline Log [total parathyroid hormone $(0.70 \mathrm{pg} / \mathrm{mL})]$ & $1.24(1.13,1.35)$ & $<0.0001$ & $1.03(0.93,1.14)$ & 0.58 \\
\hline Log [high sensitivity C-reactive protein $(1.3 \mathrm{mg} / \mathrm{L})]$ & $1.24(1.14,1.35)$ & $<0.0001$ & $1.18(1.08,1.29)$ & 0.0003 \\
\hline White blood cell (2.3 thousand/uL) & $1.36(1.25,1.49)$ & $<0.0001$ & $1.18(1.08,1.29)$ & 0.0004 \\
\hline Homocysteine $(6.1 \mu \mathrm{mol} / \mathrm{L})$ & $1.20(1.11,1.31)$ & $<0.0001$ & $1.08(0.98,1.19)$ & 0.11 \\
\hline Fibrinogen $(1.2 \mathrm{mg} / \mathrm{dL})$ & $1.38(1.27,1.50)$ & $<0.0001$ & $1.15(1.05,1.25)$ & 0.003 \\
\hline Uric acid $(1.9 \mathrm{mg} / \mathrm{dL})$ & $1.24(1.13,1.35)$ & $<.0001$ & $1.13(1.03,1.24)$ & 0.01 \\
\hline Log[myeloperoxidase $(1.1 \mathrm{pmol} / \mathrm{L})]$ & $1.17(1.04,1.30)$ & 0.006 & $1.11(1.00,1.23)$ & 0.056 \\
\hline Serum albumin $(0.5 \mathrm{~g} / \mathrm{dL})$ & $0.82(0.75,0.89)$ & $<0.0001$ & $0.98(0.89,1.08)$ & 0.74 \\
\hline Hemoglobin $(1.8 \mathrm{~g} / \mathrm{dL})$ & $0.76(0.69,0.84)$ & $<0.0001$ & $0.96(0.86,1.07)$ & 0.45 \\
\hline Hemoglobin A1C (1.5\%) & $1.35(1.25,1.46)$ & $<0.0001$ & $1.14(1.02,1.26)$ & 0.017 \\
\hline Log [HOMA- insulin resistance (0.8)] & $1.29(1.19,1.41)$ & $<0.0001$ & $1.11(1.00,1.23)$ & 0.048 \\
\hline Cystatin C (0.5 mg/L) & $1.56(1.43,1.69)$ & $<0.0001$ & $1.35(1.18,1.55)$ & $<0.0001$ \\
\hline Urine albumin ( $1.6 \mathrm{~g} / 24$ hours $)$ & $1.27(1.17,1.37)$ & $<0.0001$ & $1.06(0.97,1.15)$ & 0.21 \\
\hline
\end{tabular}

* One standard deviation

${ }^{\dagger}$ Adjusted for age, gender, race/ethnicity, cigarette smoking, physical activity, diabetes, hypertension, HDL-cholesterol, pulse pressure, eGFR, and CRIC clinic sites. 